\title{
Why Do Some Irish Drink So Much? Family, Historical and Regional Effects on Students' Alcohol Consumption and Subjective Normative Thresholds
}

\author{
Liam Delaney ${ }^{\mathrm{a}}$, Arie Kapteyn ${ }^{\mathrm{b}}$, and James P. Smith ${ }^{\mathrm{c}}$ \\ aUCD School of Economics \& UCD Geary Institute, University College Dublin, Belfield, Dublin 4, \\ Ireland; Liam.Delaney@ucd.ie; Phone 353-1-71-64631; Fax 353-1-716-1108 \\ ${ }^{\text {b} R A N D ~ C o r p o r a t i o n, ~} 1776$ Main Street, PO Box 2138, Santa Monica, CA 90407 USA; \\ kapteyn@rand.org; Phone: 1-310-393-0411, x7973; Fax 1-310-451-7084
}

\section{Abstract}

This paper studies determinants of drinking behavior and formation of subjective thresholds of acceptable drinking behavior using a sample of students in a major Irish University. We find evidence of strong associations between amounts of alcohol students consume and drinking of their fathers and older siblings. In contrast, we find little evidence of impacts of other nondrinking aspects of family background on students' drinking. Parental and older sibling drinking appears to affect subjective attitudes of students towards what constitutes problem drinking behavior. We investigated historical origins of drinking behavior including the role of the Church, English cultural influences, the importance of the brewery and distilling industry, and the influence of weather. We find relatively strong influences of the Catholic Church and English colonial settlement patterns on Irish drinking patterns but little influence of Irish weather. Historical licensing restrictions on the number of pubs and off-license establishments also appear to matter.

\section{Keywords}

Health Behaviors; Family Effects

\section{Introduction}

This paper aims to shed light on determinants of drinking behavior and the formation of subjective thresholds of acceptable or normal drinking behavior. Even in a culture such as in Ireland, where drinking is relatively common, there exists a great deal of variation in actual drinking behavior. In our sample of college students at a prominent Irish UniversityUniversity College Dublin (UCD) -5 percent of the students do not drink at all while one in seven consume on average more than two drinks every day yearly, with most of that drinking concentrated on a few days per week of very heavy drinking. For example, 8 percent of students drink 10 or more drinks on the occasions that they consume alcohol while one in five drink 7-9 drinks when they consume alcohol. Heavy student drinking is common in other countries as well. The percent of both male and female students engaged in weekly binge drinking increased steadily in the UK for the 18-24 age group over the ten year period from 1988-1998 (Egginton et al. 2002) and 28 percent of UK students engaged

\footnotetext{
${ }^{\circ}$ Corresponding author. RAND Corporation. 1776 Main Street, PO Box 2138, Santa Monica, CA 90407 USA. smith@ rand.org; Phone: 1-310-451-6925; Fax 1-310-451-6935.
} 
in binge drinking (Webb et al. 1996). The comparable number for binge drinking in the United States was 22.8 percent (Wechsler et al. 2002).

Our goal in this paper is not to explain the extent of drinking in Ireland relative to other countries, but rather why some Irish students drink so much more than other Irish students do. Our understanding of what influences the large variation in drinking behavior, even amongst a relatively homogenous sub-group of the Irish population such as university students, is quite incomplete. This raises a larger issue of the extent to which drinking of parents and older siblings shaped their attitudes toward and the actual behavior of drinking. In this paper, we are interested, in particular, in estimating the transmission of drinking behaviors within the family, but we also examine other more distant aspects of history that formed relevant dimensions of the environment in which these students grew up. These historical factors will include the role of English Culture, the Catholic Church, the Brewery industry, licensing laws, and the weather, all of which vary considerably across the places where students grew up. Our data allow us to estimate a very rich specification of the contemporaneous and historical factors influencing alcohol consumption. Drinking patterns of students' family, neighborhood, and secondary schools can not only affect the amount of drinking of students, but it may also alter their subjective assessments of what constitutes 'problem' drinking as well. We test this possibility in this paper, and find that this is an important transmission pathway of drinking behaviors of one generation within a family to the next.

A growing body of literature is pointing to the importance of subjective thresholds of normalcy of behavior in propagating population patterns of risk behavior. For example, Christakis and Fowler (2007) argue that there exist contagion effects in the spread of obesity across social networks, a finding they explain by changes in the relative normality of obesity among affected populations. Little work has been conducted examining in detail the origin of subjective appraisals of the normality of different behaviors and health states. Our study provides one of the most detailed accounts to date of how thresholds for normality of behavior are predicted by family, schooling and cultural/historical context.

The data in this paper come from a survey we designed of alcohol behaviors among students at a major university in Ireland as well as regional and school data. Besides a standard set of demographic variables, this survey gathered data on actual drinking behavior of these Irish college students along with vignette based assessments of their subjective attitudes toward drinking by themselves and by hypothetical other persons. We also obtained information about drinking of their parents and siblings. By recording information about the town that they lived in at age ten and the secondary school they attended, we can also construct measures of drinking behaviors they observed as children and adolescents that extend beyond that of their immediate family members.

The rest of this paper is divided into four sections. Section 2 explains the data utilized and measures employed in the study. Section 3 presents models of student drinking behaviors that we test documenting the relative influence of parental and sibling alcohol consumption and of pre-college environments on drinking patterns of the students. Section 4 summarizes estimates we obtained of the origins of the students' subjective attitudes toward their own drinking. The final section highlights the main conclusions.

\section{Data on Student Alcohol Consumption}

The sample for this research was recruited into a web-based survey via emails sent to all students attending a large Irish university, University College Dublin (UCD). In total, 4,450 students started the web-based survey, from March to May 2006 and 3,500 completed the full survey. The mean age of respondents is 21.5 years, and 90 percent of the sample is 
below age 25 . The gender breakdown is 45 percent male and 55 percent female. The sample of 4,450 students represents approximately 50 percent of those who use the college email system.

The sample matches closely the student population in this institution on several key variables. For example, 9.6 percent of our sample are non-Irish nationals compared to 10.2 percent of the full population and 45 percent of the sample are male compared to 46 percent of the population. The sample is slightly skewed toward undergraduate students as 20 percent of the sample are graduate students compared to 25 percent of the population and somewhat skewed toward Dublin students as 46 percent are from Dublin compared with 43 percent of the full student body. The results reported below are not changed if we restrict our sample only to undergraduates. Across all characteristics we can measure, our internet sample closely matches the full time student body of this University. In addition, in a survey conducted in all seven universities in Ireland, the drinking behaviors of UCD students was virtually identical to the full set of students in all Irish universities.

Respondents were asked several demographic and family background questions-age, gender, nationality, and year of study. Parental variables include maternal and paternal education, parental income and occupational status, current marital status, whether either parent is deceased, and if not, their current ages. Demographic data on siblings include number of siblings and their ages so that birth order of all siblings can be determined. ${ }^{1}$ Respondents were also asked the town in which they lived at age 10 and the secondary school that they attended.

\subsection{Quantity and frequency measures of drinking behavior}

The objective drinking data for this study include: measures of quantity and frequency of student drinking as well as similarly constructed measures of drinking of students' parents and their siblings over age 16. Students were asked a startup question about their own drinking: "When did you last have a drink (that is more than just a few sips)?" and given five response options; "I have never had a drink"; "Not in the past year"; "More than 30 days ago but less than a year ago"; "More than a week ago but less than 30 days ago"; "Within the last week".

The 93 percent of the sample who consumed some alcohol during the last year were asked about frequency of consumption and volume per occasion. In terms of frequency, 12 percent of respondents drink "less than once a month"; 25 percent drink "less than once a week"; 30 percent drink "once a week"; 33 percent of respondents drink "more than once a week"; and 0.66 percent of respondents drink daily. ${ }^{2}$

The second objective measure concerns drinking volume per occasion. "How many drinks containing alcohol do you have on a typical day when you are drinking?" with the permissible answers being less than $1,1-2,3-4,5-6,7-9$, or 10 or more. In terms of volume consumed; 2 percent drink less than one drink; 10 percent drink " 1 or 2"; 25 percent drink "3 or 4"; 32 percent drink "5 or 6"; 22 percent drink "7-9" and 9 percent drink " 10 or more" drinks. We used midpoints of these ranges and assigned the number 10 to 10 or more. Our basic results are not sensitive to alternative reasonable values of these assignments. Finally, total volume of drinks per year was obtained by multiplying consumption frequency by number of drinks per occasion. Similar questions were asked about drinking of mothers and

\footnotetext{
${ }^{1}$ Unfortunately in retrospect, students were not asked gender of their siblings so that we cannot test for gender specific influences of older siblings.

${ }^{2}$ For these categories, we assigned the following values in order to construct yearly drinking- daily $=365$; more than once a week $=104$; weekly $=52$; less than once a week $=26$; less than once a month $=6$.
} 
fathers and for each sibling over age 16 so that we can construct annual drinking amounts of all these immediate family members.

Before these questions on volume of drinking, half of the students were randomly assigned to a condition where they were told that a drink is ten grams of alcohol and were also given examples of types of drinks with a translation into grams. For example, a half pint of beer would be 9.8 grams and a pint would be 19.5 grams. The purpose of this split sample random assignment was to assess whether knowledge and specificity of what a drink actually is would affect answers to the drinking questions. There were no statistically significant differences between the sample of students given this information and those not given this information in terms of their description of their subjective and objective drinking behavior as well as their description of the people in the drinking vignettes.

The validity of reports about other family member drinking behaviors is given strong support in the Irish context by recent work in the Irish Affected Sib Pair Study. This study shows that reports of both sibling and parent drinking corresponded closely to clinical interviews conducted with those parents and siblings and also that use of multiple reporter ratings improves only slightly reliability compared with single reporter ratings (Prescott et al. 2005). For example, among pairs of siblings interviewed separately, the correlation in their reports of their parents drinking problems was 0.96. Similarly, the correlation among siblings in comparing their own report about themselves to that of their sibling was 0.93 . While there are always some measurement problems in all survey reports especially about others, siblings and their parents have lived together for a long time. In a culture such as Ireland, parents and their older children often drink together in pubs and at home. It is also common for siblings to drink together as well. The data in the Prescott et al. study indicates that at least in Ireland these reports about other family member drinking behavior are quite accurate.

Table 1 describes drinking behavior of students, their parents and siblings. Heterogeneity in student drinking behavior is large. Five percent of students actually do not drink at all and another 15 percent have one drink a week or less. On the other end of the spectrum, almost half of students consume five or more drinks per week, one in four more than ten drinks a week, and one in every seven more than fifteen per week. On average, Irish students who do drink consume about 351 drinks a year, or about one every day. Mirroring a well-known drinking pattern that exists in almost all societies, male students drink much more than their female counterparts - a 50 percent higher level at the mean. These gender differences are even larger at very high levels of drinking.

Data from the survey of students in the Seven Irish Universities study that we conducted (all universities in the Republic of Ireland) reveal that UCD students are not unusual in their drinking intensity. Using the same measure of annual frequency, 534 UCD respondents to the Irish Universities Study drank an annual mean amount of 338 drinks (compared to a mean of 334 in our data). ${ }^{3}$ This compares to a mean annual amount of 316 drinks among 983 respondents in the other six universities combined, with mean drinking in two of the seven colleges being higher than UCD.

Similarly, in a study of drinking patterns of American college students, Wechsler et al. (2002) report that 52 percent of them drink four or more drinks on a single occasioncompared to 40 percent of Irish students in our sample reporting five or more drinks on a single occasion. Finally, Webb, Ashton and Kamali (1996) administered a survey to 3,075 second-year students from ten UK universities. Among those who did drink, 61 percent of

\footnotetext{
${ }^{3}$ There are no data on parental drinking in the Irish Universities Study
} 
males and 48 percent of females exceeded the respective recommended weekly alcohol consumption levels. Thus, the drinking of the Irish students in our sample is not atypical of all Irish students or students in the United States or the United Kingdom. Instead, the atypical aspect of our sample is the quality and detail about drinking of other family members and the ability to measure other background factors that may be related to drinking.

Not surprisingly, fathers drink much more than mothers do. Gender discrepancies are higher among parents than students, a reflection of the larger secular increase in drinking among women. Both parents drink less than their college attending sons and daughters. In part, this may be due to the well-established pattern of declines in drinking with age (Ramstedt and Hope 2005). But it is also a consequence of a recent surge in drinking when Ireland earned the label "Celtic Tiger." Young people are understandably more sensitive than their parents to the greater availability of money as their drinking habits are formed. This secular increase in Irish drinking is so large that these college attending female students actually drink a little more than their fathers do and 75 percent more than their mothers.

Students with no older siblings drink 280 drinks per year, compared to 342 drinks for those who have older siblings (data not shown). There exists considerable variation in the amount of drinking reported about the oldest and second oldest sibling (given that they are older than the student respondent). More than a fifth of older siblings have more than ten drinks a week while about one in nine does not drink during the year. There is almost no difference in the amount of drinks reported about these two siblings who are reasonable close in age. While at first glance one might be puzzled by the lower drinking volume among older siblings compared to students, we show below that even amongst our college students drinking declines with age. ${ }^{4}$ Drinking is also known to decrease with the end of the college experience.

\subsection{Subjective measures of drinking}

In addition to telling us about the quantity of drinks they consumed, student respondents were also asked to rate their own drinking on an ordered qualitative scale using the question: (2) "How would you describe your own drinking patterns over the course of the last year?" Mild, Moderate, Some Cause for Concern, Excessive, Extreme. 26.9 percent describe drinking as mild; 43.9 percent as moderate; 18.5 percent as some cause for concern; 9.6 percent as excessive; 1.5 percent as extreme.

Having subjective measures of drinking alongside objective measures described above is important for several reasons. By combining this subjective data on problem drinking with the data on actual drinking, we can learn a good deal about the pathways through which parental drinking habits influence the drinking of their offspring. For example, some students who drink a lot may not perceive that they are drinking in excess or have a drinking problem. Drinking patterns that they observed among their parents and siblings may not have only influenced the amount they consumed, it may also have affected the translation of a particular amount of drinking into a subjective scale of whether or not that drinking constitutes a 'problem' behavior. If they view a given level of drinking as less of a problem due to the heavy drinking of their parents, they may well feel free to drink more themselves.

We will provide empirical tests of this hypothesis by using the subjective evaluation of a student's own drinking along with some vignette questions that were given to students about the drinking behavior of hypothetical peers. The vignette drinking questions are of the form

\footnotetext{
${ }^{4}$ This may also be partly due to heavy drinking students dropping out of college.
} 
(3) [John/Mary] is out on a given night and has [1 or 2, 3 or 4, 5 or 6, 6 or 7, 10 or more] drinks containing alcohol. Is [John/Mary]'s drinking habit-Mild, Moderate, Some Cause for Concern, Excessive, Extreme Since both expressions in square brackets are varied randomly across respondents, vignettes vary in the number of drinks mentioned and the name (implying gender) of the hypothetical person.

Vignettes in (3) use the same scale as in (2) for respondents' own drinking. Because all students evaluated the same hypothetical vignette persons (whose drinking behavior is identical), we can test whether scales that students use to characterize the same drinking are influenced by drinking patterns of their relatives. ${ }^{5}$ This analysis rests on an assumption that scales that students use in evaluating the hypothetical vignette person are the same as what they use for themselves. This assumption is called response consistency. Van Soest et al. (2011) show that there is strong support for this assumption in this data.

\subsection{Geographic and secondary school Data}

Data on the name of the town students lived in at age ten and the secondary school they attended before coming to college were used to describe drinking and other relevant aspects of the spatial environment in which students grew up. With this information on towns, we can match our student survey to external data on attributes of towns, particularly as they are related to drinking behaviors of residents of that town. The geography based variables are described in detail in the next section.

All towns, of which we have 305 distinct names, were also aggregated into their administrative counties, of which there are 36 in Ireland. Administrative counties are areas drawn up for the purposes of local government being responsible for road maintenance, public land use, planning decisions, waste management. In Ireland, state data are usually compiled at administrative county level. ${ }^{6}$ Similarly, data on secondary schools attended were matched to external data describing whether the school was single sex (and if so which gender), the religious denomination of the school (Catholic, Church of Ireland, interdenominational, Jewish, or Quaker), and whether the school was a boarding school or a partial boarding school. ${ }^{7}$

Peer group influences have been a recent theme in the economic literature on student behaviors (Blanchflower et al. 2009; Etile 2007; Kooreman 2007; and Lundborg 2006). Drinking of friends at school is also known in our data but there are no possible variables in our data that could be used to randomly assign friends or to identify peer effects on drinking behavior. In our sample, parental drinking behaviors explain friends drinking just as well as the students drinking, suggesting that these students apparently select friends with very similar drinking habits to their own. The influences of peer drinking are implicitly introduced through the geographic and secondary school controls explained above.

\footnotetext{
${ }^{5}$ The use of web-surveying allows for an experimental design to test the importance of various dimensions. We randomly assigned levels of severity according to frequency of drink, and the male or female names in the vignettes.

${ }^{6}$ In Ireland administrative counties are usually the same as traditional geographic regions termed counties. There are two exceptionsDublin County is divided into four administrative counties (Dun Laoghaire-Rathdown, Fingal, South Dublin and Dublin City) and Tipperary has two discrete local authorities-North and South Tipperary.

7 According to information provided by the Department of Education and Science (2004)for the school year 2005-2006, there are 733 post-primary schools in Ireland. There are 146 girls' schools ( 20 percent), 109 boys' schools ( 15 percent) and 478 mixed schools (65 percent). There are 372 Catholic schools (51 percent), 25 Church of Ireland schools (3 percent), one Jewish school (.1 percent), one Quaker school (.1 percent), and 334 inter-denominational schools (46 percent).
} 


\section{Empirical Models of Drinking Behaviour}

\subsection{Econometric specification}

We begin by estimating a model of our best objective measure of student drinking- yearly volume of drinks. The model takes the following form:

$$
Y_{i t j}=a_{i}+\beta X_{i t}+\psi Z_{i t-1}+\lambda_{j 0}+s_{i o}+\varepsilon_{i t j}
$$

Drinking for student $\mathrm{i}$ from region $\mathrm{i}$ in the current period $\mathrm{t}$ is a function of contemporaneous $\left(\mathrm{X}_{\mathrm{it}}\right)$ and lagged $\left(\mathrm{Z}_{\mathrm{it}-1}\right)$ demographic attributes of students: age, gender, religiosity, ${ }^{8}$ and whether they are an Irish citizen. The following family background variables were used to describe the mother and father of students-years of schooling, age, whether deceased, parents' income, and whether parents were separated or divorced. We included variables measuring number of siblings and birth order of respondent. ${ }^{9}$

Most important, we model students' drinking as a function of family drinking behaviors preceding their own-our similarly constructed objective measure of drinking of fathers, mothers, oldest and second oldest sibling. Older siblings are used as we want siblings' drinking to be established prior to students' drinking and this is more likely to be true for older siblings. This gives greater confidence that the relationship being picked up is a transmission mechanism rather than a common unobservable factor.

As described above, we include several measures of the geographic $\left(\lambda_{\mathrm{jo}}\right)$ and secondary school environment $\left(\mathrm{s}_{\mathrm{io}}\right)$ of a student-whether the secondary school was single sex, the religious denomination of the school, and whether the school was a full or partial boarding school. Our geographic indicators are either defined at the town or county level as data availability dictates. ${ }^{10}$

\subsection{Demographic effects}

The right hand side of Table 2 contains estimated coefficients and associated robust standard errors obtained in models of yearly volume of student drinking. Details for the construction of all variables not directly explained in the text are available in Appendix Table 1. All models are estimated combining men and women and then estimated separately by gender. Robust standard errors are used. We briefly summarize results for non-drinking related background variables, then move in sequence to family, school and regional effects.

The age of a student is negatively related to yearly volume of drinks, a not uncommon finding about student drinking. Not surprisingly, female students drink significantly less than male students do (controlling for other co-variates, 108 fewer drinks per year). Part of the gender difference in drinking is related to biology (size and body weight) which is one reason that official NIAAA thresholds for binge drinking on a single occasion differ for men (five drinks) and for women (four drinks).

This gender difference is about the same as the unadjusted gender difference in Table 1, so that taken together variables in this model explain little of gender differences in drinking. This is not surprising as male and female students mostly share common family and

\footnotetext{
${ }^{8}$ Respondents were asked to rate themselves on a five point scale ranging from 1. Devout 2. Practising 3. Formal Practising 4. Indifferent 5. Atheist. This was recoded to give a five point scale going in the direction of religiosity.

${ }^{9}$ In preliminary models, we included student income as a variable but it was never statistically significant.

${ }^{10}$ Missing value indicators were included in all models indicating that data were not available for a variable. In particular, foreign students are given missing values for the all geographic and secondary school indicators along with the dummy variable indicating that they are non-nationals.
} 
neighborhood backgrounds. In contrast, foreign students attending this university (who do not share a common background with native born Irish students) also drink significantly less than Irish nationals do (92 drinks per year), an effect that is somewhat larger for boys than for girls. Variables in the model explain about two-thirds of the raw drinking differential of 133 drinks by nationality. This is mainly due to the background drinking behavior of the family-i.e., parents and older siblings of Irish students drink far more than parents and siblings of foreign students. These gender and nationality differences in drinking volume are large and robust to model specification. Finally, the more religious a student is the less he or she drinks. ${ }^{11}$

\subsection{Parental and sibling transmission}

Putting aside for a moment any possible influence of parental drinking, we find relatively small effects of other parental background variables on how much their college attending children drink. Neither father's education, mothers' age, whether a parent is still married, and parental incomes have any statistically significant effects on students' drinking. The yearly number of student drinks is positively associated with mothers' education (at least for boys) and with being later in the birth order. All in all, it is not an unfair summary that, conditional on parents' and siblings' drinking, conventional measures of family background have only modest explanatory power in explaining the amount that Irish students drink.

While this collection of measures of students' family background has little impact on student drinking, this is decidedly not so for volume of drinks consumed by parents and older siblings. We find that drinking of mothers significantly impacts the number of drinks consumed by both female and male students about equally. But drinking of fathers appears only to influence drinking of their college attending sons. One interpretation is that mother's drinking is a proxy for unobserved family effects and the significant effect of mother's drinking would then be more of an indicator of a more generic set of problems within the family. We return to this below. In addition, in our models parental drinking amounts have just as much influence on seniors as on freshmen at this school indicating no decay in the influence of parents drinking as a function of years attending college.

Estimated effects of sibling drinking are large and statistically significant and affect male and female students equally. This finding is supported by Trim et al. (2006) who report that older siblings drinking influenced their younger siblings drinking, but younger sibs only had an influence on older sibs if they were close in age. Since parents affect drinking of older siblings, which in turn affects students, the total impact of parents on drinking of these college students is even larger, as we would have to add in the indirect impact of parents influence on older siblings. To illustrate, if we delete sibling drinking variables from the model in Table 2 the estimated effect of mothers drinking rises to .17 and fathers' drinking increases to .11. However, as the results in Table 2 attest, siblings' drinking has an independent association with student drinking even when parents' drinking is controlled.

\subsection{Schooling effects}

There are several attributes of secondary school attended in this model. The secondary school attended does appear to matter for subsequent college age drinking, but only for boys. The strongest effect is from attending a full boarding school (mostly boy schools in Ireland) which is associated with significantly more drinking in college for boys. Similarly, boys who attend all boys schools also drink more in college than other male students. Statistically weaker effects are found for those attending Church of Ireland schools (the left

\footnotetext{
${ }^{11} \mathrm{We}$ also estimated the model using dummy variables for the religiosity variable. The estimated coefficients of all other variables were robust to this change.
} 
out group are Roman Catholic schools). These estimated effects when taken together suggest that in addition to possible selection effects the culture of secondary schools may matter in the promotion of greater amounts of drinking of young men. ${ }^{12}$

\subsection{Geographical and historical context}

Family and school are not the only aspect of background that may influence drinking of young people. There exists a great deal of geographic variation in drinking in Ireland, rooted deep in Irish history the origin of which is in dispute. To illustrate, Figure 1 plots diversity in drinking across Irish counties. Variation is large-often a factor of two to one across the counties. Drinking is heaviest in Dublin and the Munster counties in the South (Cork and Waterford) as well as Kilkenny and lowest in counties in the center and in Donegal and Monaghan towards the North. Mean income per county does not offer much of an explanation for these geographic patterns (results not shown). Putting aside that Irish men drink far more than Irish women do, geographic correspondence between drinking of men and women is not high in Ireland. A lot of social drinking historically in Ireland was within gender and the correlation between male and female mean drinking by county is only .25 .

We divide factors that may explain the historical roots of Irish drinking as revealed by this geographical pattern of drinking into four groups-religion, the role of English cultural influence, the brewing and distilling industry, and the weather.

Religion has historically played a significant role in Irish life, but one that is far from uniform across time and place. A potential proximate cause of regional variation in Irish drinking may be the differential power of the Catholic Church. The Church played a strong role in attempting to suppress and contain alcohol consumption throughout Irish history. For example, during confirmation, many young catholic boys and girls took the 'pledge', a lifetime vow to abstain from alcohol. Some — but not all—adhered to that pledge. Sermons from the pulpit often would select as the theme the evils of the drink.

We proxy the influence of religion with two variables. First, we measure the number of Catholic masses per capita in each town during each week. We also rely on results of an important referendum - the 1996 vote to permit divorce in Ireland. This controversial measure - strongly opposed by the Catholic Church—split the country and only passed by the slimmest of margins. Not surprisingly, support was strongest in Dublin and its surrounding counties and weakest in the more traditional counties of the West. Both variables behaved as expected. An increase in number of masses reduces drinking while a larger county vote in favor of the divorce law increases drinking. These variables are jointly significant at the ten percent level with an $\mathrm{F}$ value of 2.38. Estimated religion effects are larger for female compared to male students.

The influence of the Catholic Church and the English is closely inter-twined and affects the extent to which different regions of the country are differentially religious. With respect to regional differences in the historical influence of English culture, we have two measures. The first is whether the town has a cricket club, a distinctly British and not Irish institution. Another hypothesis is that towns outside the boundaries of the Anglo Norman "Pale" were more likely to come under full Catholic control. The Pale is that region of Ireland that was predominately British for most of the 1400 and 1500's and was the main repository for British culture and administration. Importance of the "Pale" would supply evidence that heavy drinking practices may have been imported from the UK and that heavy Irish drinking was partly imported through the influence of British culture. Table 2 shows that both having

\footnotetext{
${ }^{12}$ Selection effects may also be operative in who attends these schools.
} 
a cricket club and being inside the Pale are associated with increased drinking, lending some support to this hypothesis.

Variations in development of the Irish brewing and distilling industry may be a factor in regional patterns of drinking. Historically the cost of transporting alcohol was highly dependent on distance from the local brewery. We proxy this potential influence with two measures - whether the settlement had its own brewery in 1902 (Brewery), and whether the settlement had its own distillery in 1902 (Distillery). Neither is statistically related to current student drinking.

Distribution of alcohol in the form of public houses and off-licenses (the equivalent of liquor stores) is another potential source of regional variation and one that is vital in policy debates about the role of alcohol supply in determining consumption. While demand and supply factors typically combine to determine equilibrium quantities, in Irish history, the licensing of the number of pubs has been severely regulated and restricted over time. Licensing laws in Ireland in the $20^{\text {th }}$ century made entrance and exit from owning a public house rare as the number of licenses was fixed and transfer of license across regions was not permitted under legislation dating back to the late 1800's. Thus, it is reasonable that the number of pubs and off license establishments are supply constrained in the Irish context.

We measure current conditions by examining the number of people per pub in each county. This index is highest in Meath, Kildare, Wicklow and Dublin with over 400 people per pub each and drops to less than 200 people per pub in Mayo and Roscommon. This is not indicative of current demand patterns as entry and exit have been constrained due to licensing restrictions, but do reflect inertia in distribution of license resulting from this legislation. Similarly, off licence outlets are restricted by Irish law requiring a vendor to attain a scarce license to open one up. The results in Table 2 indicate that both of these supply restrictions have some bite. An increase in the number of allowable pubs and off licence establishments, both partly fixed by Irish law, increases the volume of drinks by students even though most of them are currently located in and around Dublin and not in their home towns.

Another geographically related factor is the influence of weather. Irish weather is notorious not only for abundant rainfall, but its dampness and cold, factors that were even more important historically when heating was a major problem in Irish homes. There are contrasting and largely untested views on the role of weather on Irish drinking. One is that excessive Irish drinking was partly an escape from the harshness of its cold and damp climate. The other view is that warm weather and lack of rainfall may be factors that encourage people to leave their houses and engage in social drinking so that rainfall and cold may actually discourage drinking.

Irish weather is far from uniform. Variation in rain is pronounced with heavier rainfall concentrated along the West Atlantic coast and in the more mountainous areas. In contrast, sunshine shows a rather marked increase as one moves from the North-West to the SouthEast. In spite of common folklore, we find no effect of Irish weather on the drinking of the students.

\subsection{Instrumental variable estimates}

It is important to recognize that our estimated effects of drinking by siblings and by parents in particular on student drinking in the left hand side of Table 2 are not necessarily causal. It may instead reflect the influence of other unobserved factors associated with problems in the family that make parents, older siblings, and students drink more. We have argued that the historical factors outlined above had a key role in fixing geographical drinking patterns in 
Ireland. This argument suggests that geographic determinants of historical drinking patterns may serve as instruments for drinking of mothers, fathers, and siblings of these students.

To investigate this, we estimated IV models of student drinking where we instrumented fathers', mothers', and older siblings' drinking as a function of all exogenous geographic variables that influence drinking and their interactions with all other exogenous variables. Since we also include the geographic variables directly in the drinking equation, the excluded variables are only the interactions of the geographic variables with other exogenous variables. To investigate the validity of the instruments we perform both overidentifying tests and tests for weak instruments. The over-identifying restrictions are never rejected at the 5 percent level (p-values are. 34 for men and .26 for women). We considered various diagnostics for weak instruments. We note that partial $\mathrm{R}^{2}-\mathrm{s}$ of the first stage regressions vary between .07 and .10 for the whole sample, between .12 and .18 for men, and between .11 to .12 for women. Under-identification tests (Anderson canonical correlation test and Cragg-Donald $\mathrm{N}^{*}$ minEval test) reject at the 5 percent level for the whole sample and for women, and at the 10 percent level for men. Thus it appears that we cannot reject the over-identification restrictions implied by the model, whereas the various tests for weak instruments lead to rejection.

Our IV results are listed in the right hand side of Table 2 . We observe that generally the estimates in Tables 2 for the non-instrumented variables and instrumental variables models are qualitatively similar, so that our previous discussion applies to the non-instrumental variable results presented in Table 2. Comparing IV and non-IV coefficients for older siblings shows that the differences are modest; both the effects of siblings' drinking continues to have a significant and substantial effect on the student's own drinking in the IV model. Somewhat foreshadowed by a weaker fit in the first stage, standard errors of the coefficients of parents' drinking increase in the IV model. However, coefficients for father's drinking increase and now appear to be approximately the same for male and female student drinking.

The most dramatic change is observed for the influence of mother's drinking which is statistically insignificant in the all student IV model. This suggests that observed effects of mother's drinking in the non-IV model in Table 2 may be an artifact and not an actual transmission from drinking of mothers to children. Mother's drinking may be a proxy for unobserved family effects centered on behaviors of mothers (Currie and Moretti, 2003), but does not have a clear causal effect on student drinking. Our finding on parents may suggest a direct causal link between drinking of fathers and children, but that mothers' drinking may instead be capturing some dimensions of problems in family life.

Since our central goal in this research is to isolate transmission of family drinking behaviors to these students, it is a legitimate question to ask whether there are other types of unobserved heterogeneity that may be correlated with both parental and student drinking. While one can never completely rule out all possible forms of heterogeneity, the most obvious source of concern would be those associated with where people live since that is in common with both students and their parents. To test this, we re-estimated our OLS and IV models by first controlling for county fixed effects and then controlling for town fixed effects. The results for the family member drinking variables are contained in Table 3 . As one can readily see, these results are extremely close to those obtained in the OLS and IV models in Table 2 . Thus, we are reasonably confident that the family transmission pathways that we have estimated are not picking up unobserved factors associated with the county or town where the family lived. 


\section{Subjective Drinking Status and Vignette Thresholds}

\subsection{Anchoring vignettes}

Besides telling us the quantity of drinks they consumed, student respondents were also asked to rate their own drinking during the last year using an ordered qualitative scale with the following categories Mild, Moderate, Some Cause for Concern, Excessive, Extreme.

Having subjective measures of drinking alongside objective measures is important since some students who drink a lot may not perceive they are drinking in excess or have a drinking problem. Moreover, the drinking they observed among their parents and older siblings may not have only influenced amounts they consumed, it may have affected the translation of a particular amount of drinking into their subjective rating of whether that drinking constitutes a 'problem.' If they think their heavy drinking is less of a problem because their parents drank a lot, this alteration in their subjective attitudes is one reason for their heavy drinking.

This issue can be addressed with anchoring vignettes (King et al. 2004; Kapteyn et al. 2007). Vignettes describe hypothetical students where we varied the amount of drinking the person described in the vignette engaged in. With each vignette, students were asked to rate the degree of problem drinking of the vignette person using the same scale on which they rated themselves. To illustrate, Table 4 lists distributions of responses to vignettes that indicated the hypothetical student was drinking 7-10 drinks on that occasion. The first column lists percent distribution of ratings of all students (independent of their own drinking behavior). Almost 39 percent of all students thought that 7-10 drinks were either excessive or extreme.

In the next columns, distribution of responses are provided but limiting the sample to students who themselves reported they drank 7-9 drinks per occasion. For these students, the distribution of ratings is listed not only for the vignette persons but also for students' rating of their own drinking problems. Students who themselves drink 7-9 drinks per occasion are much less severe in their evaluation of students described in the drinking vignettes. Instead of 39 percent rating the drinking in the vignette as excessive or extreme, only 19 percent of students who engage in the same drinking behavior find it excessive or extreme. This distribution of ratings of vignette persons is virtually identical to their subjective ratings of their own drinking (they are not statistically different) suggesting that these students are using the same scale in rating vignette persons as they use on themselves. 13

The remaining three columns in Table 4 provide the distribution of ratings except that we now stratify not by the volume of drinking of students but by amount of drinking of mothers, fathers, and older siblings of students. In particular, the distributions in these columns are now for fathers, then for mothers, and then for older siblings who themselves consumed 710 drinks per occasion. Once again, students whose parents or older siblings drink in the same volume as the students described in the drinking vignettes are much more tolerant of high amounts of drinking.

\subsection{Demographic effects on subjective thresholds}

To test these ideas more formally, Table 5 lists results obtained by modeling students' subjective evaluation of their self-rated drinking problem on the mild, moderate, some cause of concern, excessive, and extreme scale. This model is estimated using ordered probits

\footnotetext{
${ }^{13}$ Response consistency implies a similar distribution of responses whether the vignette or student respondent is described. Van Soest et al. (2007) formally tested response consistency in our data of Irish students and could not reject the assumption of response consistency.
} 
treating the outcome as an ordered scale where increases in the scale correspond to a greater drinking problem. Table 6 models a subjective scale using ordered probits in the same way but now the scale refers to their evaluation of the quantity of drinks of persons described in vignettes.

If there were small or no effects of co-variates on thresholds students use in making their subjective evaluations, then we would expect that the signs of the effects of variables would be similar in Table 2 (OLS model) and Table 5 (the objective and subjective drinking models). For example, women report less of a drinking problem in Table 5 and also consume fewer drinks in Table 2. But foreign students drink much less (Table 2) than native-Irish students' drink, but they do not report statistically significant less of a drinking problem in Table 5.

The reason can be obtained from coefficients in Table 6 which show that for the same drinking behavior described for a student in a vignette, foreign students are more likely to say that this constitutes a problem. Even though foreign students drink much less than Irish national students, because they have tougher thresholds on what constitutes a drinking problem, they rate themselves the same on a subjective drinking problem scale as do the Irish national students. Table 6 demonstrates that tougher evaluations of same drinking behaviors are characteristic of more religious students and when a female name is used in a vignette instead of a male name. ${ }^{14}$

\subsection{Family effects on subjective thresholds}

Our primary interest lies in family drinking patterns. While drinking of parents is associated with a higher likelihood of self-rated drinking problems by students, these effects are not as dramatic as in the volume of drink model in Table 2. In fact, father's drinking amounts in Table 5 has no statistically significant effect on the probability of self-rated problem drinking by a student. The reason is apparent from Table 6 as both fathers and mothers amount of drinking makes students 'softer' about what constitutes a drinking problem, even after controlling for all other co-variates. The same is true about the drinking of older siblings.

The data in Table 7 offer another perspective on this issue. The right hand side models in Table 7 are the same county fixed effects estimates of quantity of drinking presented in Table 3. The left hand side set of models contain the same set of co-variates with one addition- the students subjective assessment of his or own drinking problem. Thus, the estimated family effects in the left hand side models represent effects of family drinking behaviors controlling for any change family drinking had on the students own subjective threshold of whether he or she had a drinking problem. These results suggest that a significant reason why parental and older siblings drinking affects that of these students is by lowering students' thresholds of what constitutes problem drinking.

These data suggest that subjective attitudes toward drinking are influenced by drinking behaviors students observed in their home. Students whose parents drink more are less harsh in their evaluation of their own drinking. Lowering thresholds of what constitutes problem drinking (which is influenced by drinking patterns observed in the family home) is one reason why these students feel less constrained in their own alcohol consumption. This also implies that distributions of self-reported problem drinking understate the tails of the true distribution of drinking problems. If response thresholds of the median drinker were used to evaluate drinking amounts of the full population, there would be more people who would be

\footnotetext{
${ }^{14}$ This is true for male and female students. This may reflect cultural differences in attitudes toward male and female drinking or a biologically accurate belief that given their smaller stature drinking capacity is less for women.
} 
seen as having no problem at all and many more who would be designated as problem drinkers.

\section{Conclusion}

In this paper, we attempt to account for patterns of drinking and subjective normative thresholds observed among students in an Irish University that were obtained from an Internet survey we designed. There is considerable variation in levels of drinking among these students. At a conventional level, we find that boys drink more than girls do and that Irish nationals drink more than foreign students. We also find that boys who go to either all boys schools, boarding schools or Church of Ireland schools drink substantially more than other male students.

We find evidence of strong associations between amounts of alcohol students consume and the drinking of their fathers and older siblings. In contrast, we find little evidence of any impact of other non-drinking aspects of family background on the students drinking. Parental and older sibling drinking also appears to affect subjective attitudes of students towards what constitutes problem drinking behavior. Students whose parents or older siblings drink more are softer on what is a drinking problem when evaluating their own objective drinking behavior. Since the effect of mother's drinking in the student's drinking equation is weaker when using instrumental variables, we have suggested that the significant effect of mother's drinking on alcohol use by children in ordinary regression simply proxies unobserved family effects, e.g. problems not captured by our observed variables.

We also investigated the historical origins of drinking behavior. Our exploration examined the role of the Church, English cultural influences, the importance of the brewery and distilling industry, and the influence of weather. We find relatively strong influences of the Catholic Church and English colonial settlement patterns on patterns of Irish drinking but little influence of patterns of Irish weather. Historical licensing restrictions on the number of pubs and off-license establishments also appear to matter.

Overall, our results point to a pattern of transmission of parental drinking and sibling drinking affecting both actual alcohol consumption and standards for what is considered normal or acceptable drinking behavior. Our results also point to complex deep-rooted cultural and historical factors that facilitate alcohol consumption and explain variation even among the student sample. Such variation explains behavior to a greater degree than it explains subjective thresholds and points to a role of regional-level culture and history in this context in facilitating the development of drinking rather than necessarily affecting people's normative thresholds, which are more universal across the sample. However, the role of national-level culture in influencing thresholds is borne out by the very large effect of being Irish on standards of acceptable drinking compared to foreign students. Understanding the development of subjective thresholds and their role in actually determining behavior is a key avenue for future research.

\section{Acknowledgments}

This research was supported by grants from the National Institute on Aging and the Irish Higher Education Authority. Thanks to Colm Harmon, Patrick Wall for useful comments. Fearghal O'hAodha and David Comerford provided excellent research assistance. There are no conflicts of interests.

\section{References}

Blanchflower DG, Oswald AJ, Van Landeghem B. Imitative obesity and relative utility. Journal of the European Economic Association. 2009; 7:528-538. 
Christakis NA, Fowler JH. The spread of obesity in a large social network over 32 years. New England Journal of Medicine. 2007; 357(4):370-379. [PubMed: 17652652]

Currie J, Moretti E. Mother's education and the intergenerational transmission of human capital: evidence from college openings. Quarterly Journal of Economics. 2003; 118(4):1495-1532.

Department of Education and Science. A brief description of the Irish education system. Dublin: Department of Education and Science. 2004. Retrieved 14 ${ }^{\text {th }}$ August 2007 from: http://www.cidb.ie/ live.nsf/0/802567ca003e043d80256e6d002f9b59?OpenDocument

Egginton R, Williams L, Parker H. Going out drinking: the centrality of heavy alcohol use in English adolescents' leisure time and poly substance taking repertoires. Journal of Substance Use. 2002; 7(3):125-135.

Etilé F. Social norms, ideal body weight and food attitudes. Health Economics. 2007; 16:945-966. [PubMed: 17605138]

Kapteyn A, Smith JP, Van Soest A. Vignettes and self-reported work disability in the US and The Netherlands. American Economic Review. 2007; 97(1):461-473.

Kooreman P. Time, money, peers, and parents: some data and theories on teenage behavior. Journal of Population Economics. 2007; 20:9-33.

Lundborg P. Having the wrong friends? Peer effects in adolescent substance use. Journal of Health Economics. 2006; 25:214-233. [PubMed: 15964090]

King G, Murray CJL, Salomon JA, Tandon A. Enhancing the validity and cross-cultural comparability of measurement in survey research. American Political Science Review. 2004; 94(1):191-207.

Prescott CA, Sullivan PF, Myers JM, Patterson DG, Devitt M, Halberstadt LJ, Walsh D, Kendler KS. The Irish affected sib pair study of alcohol dependence: study methodology and validation of diagnosis by interview and family history. Alcoholism: Clinical and Experimental Research. 2005; 29:417-429.

Ramstedt, M.; Hope, A. The Irish drinking culture—drinking and drinking-related harm, a European comparison. 2005. Unpublished paper

Trim RS, Leuthe E, Chassin L. Sibling influence on alcohol use in a young adult, high-risk sample. Journal of Studies on Alcohol. 2006; 67(3):391-398. [PubMed: 16608148]

Van Soest A, Delaney L, Harmon C, Kapteyn A, Smith JP. Validating the use of vignettes for Subjective Threshold Scales. Journal of the Royal Statistical Society Series A. 2011; 174(3):575595.

Webb E, Ashton CH, Kelly P, Kamali F. Alcohol and drug use in UK university students. The Lancet. 1996; 348:922-925.

Wechsler H, Lee JE, Kuo M, Seibring M, Nelson TF, Lee H. Trends in college binge drinking during a period of increased prevention efforts: findings from 4 Harvard School of Public Health College Alcohol Study Surveys, 1993-2001. Journal of American College Health. 2002; 50(5):203-217. [PubMed: 11990979]

\section{Appendex A}

Description of Covariates

\begin{tabular}{|l|l|}
\hline Covariate & Description \\
\hline Age & Integer Age. "What is your age?" \\
\hline Gender & "What is your gender?"1=Female, 0 = Male. \\
\hline Fathers Education & $\begin{array}{l}\text { "What is the highest level of education your father attained?"1=Primary, 2=Lower } \\
\text { Secondary, 3=Upper Secondary, 4=Higher Education/University. These variables } \\
\text { are recoded to represent average years of education. }\end{array}$ \\
\hline Mothers Education & $\begin{array}{l}\text { "What is the highest level of education your mother attained?'1=Primary, 2=Lower } \\
\text { Secondary, 3=Upper Secondary, 4=Higher Education/University. These variables } \\
\text { are recoded to represent average years of education. }\end{array}$ \\
\hline Nationality or Foreigner & $\begin{array}{l}\text { "Which of the following best describes your situation?"1=Irish national, 2=Foreign } \\
\text { national studying for a full qualification in Ireland, 3=Foreign national studying as }\end{array}$
\end{tabular}




\begin{tabular}{|c|c|}
\hline Covariate & Description \\
\hline & $\begin{array}{l}\text { part of an exchange program. Condensed to "Non-National" ( }=1 \text { if Foreign national, } 0 \\
\text { if Irish National) }\end{array}$ \\
\hline $\begin{array}{l}\text { Fathers Annual Alcohol } \\
\text { Volume }\end{array}$ & $\begin{array}{l}\text { Combined from two questions: Does your father consume alcohol? } 1=\text { Abstainer, } 2= \\
\text { Consumes Alcohol Less than Once a Month, } 3=\text { Consumes Alcohol Less than once } \\
\text { a week, } 4=\text { Consumes Alcohol Once a Week, } 5=\text { Consumes Alcohol More Than } \\
\text { Once A Week, } 6 \text { = Consumes Alcohol Daily, Roughly how many drinks does your } \\
\text { mother consume each time she is drinking" - Integer Amount }\end{array}$ \\
\hline $\begin{array}{l}\text { Mothers Annual Alcohol } \\
\text { Volume }\end{array}$ & $\begin{array}{l}\text { Combined from two questions: Does your mother consume alcohol? } 1=\text { Abstainer, } 2 \\
=\text { Consumes Alcohol Less than Once a Month, } 3=\text { Consumes Alcohol Less than } \\
\text { once a week, } 4=\text { Consumes Alcohol Once a Week, } 5=\text { Consumes Alcohol More } \\
\text { Than Once A Week, } 6 \text { = Consumes Alcohol Daily. "Roughly how many drinks does } \\
\text { your father consume each time he is drinking" - Integer Amount }\end{array}$ \\
\hline Parental Income & 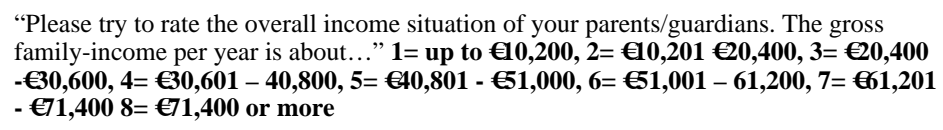 \\
\hline Parental Marital Status & "Are your parents separated?" $1=$ Yes, $0=$ No. \\
\hline
\end{tabular}



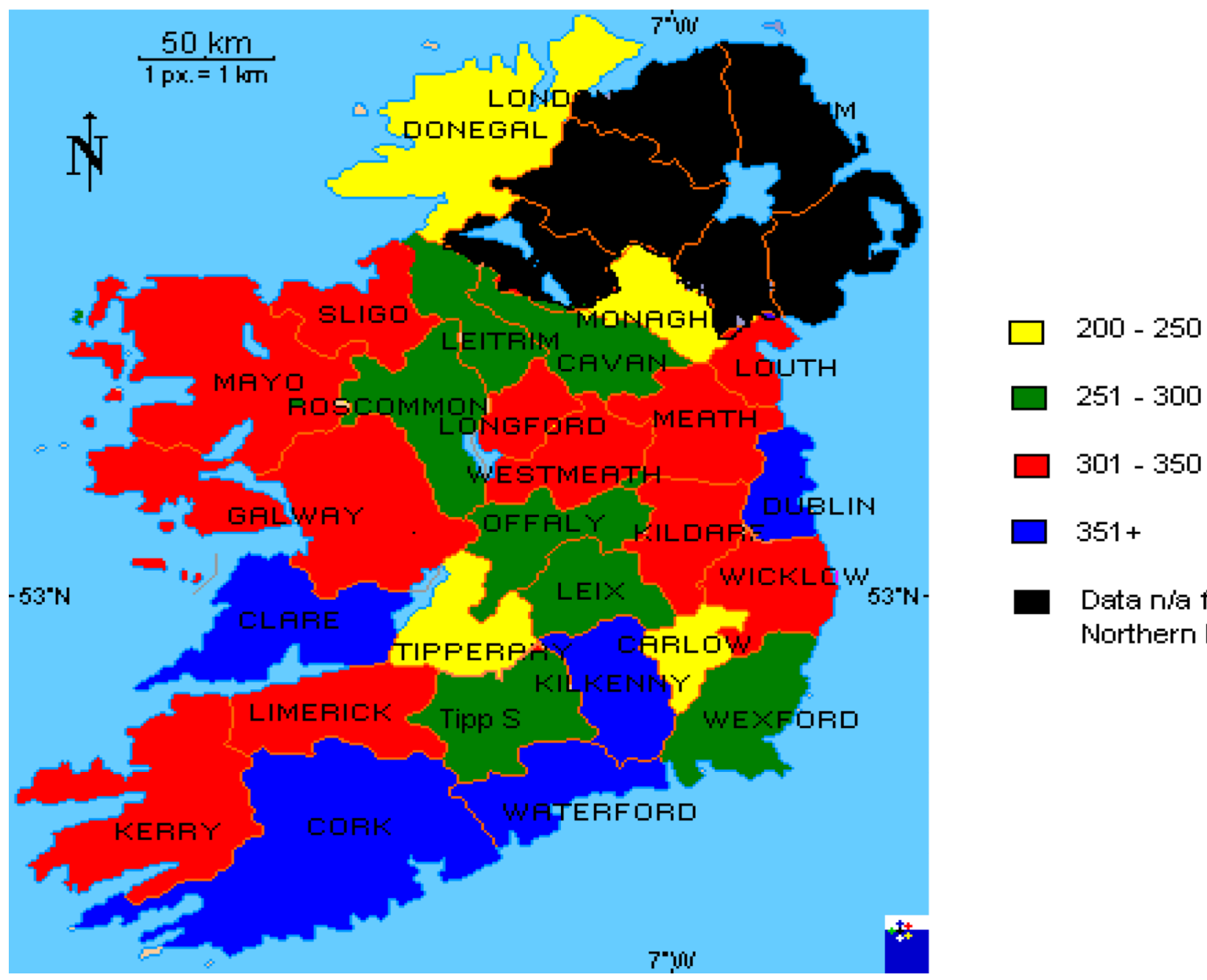

$251-300$

Figure 1.

Annual Volume of Drinking by County 


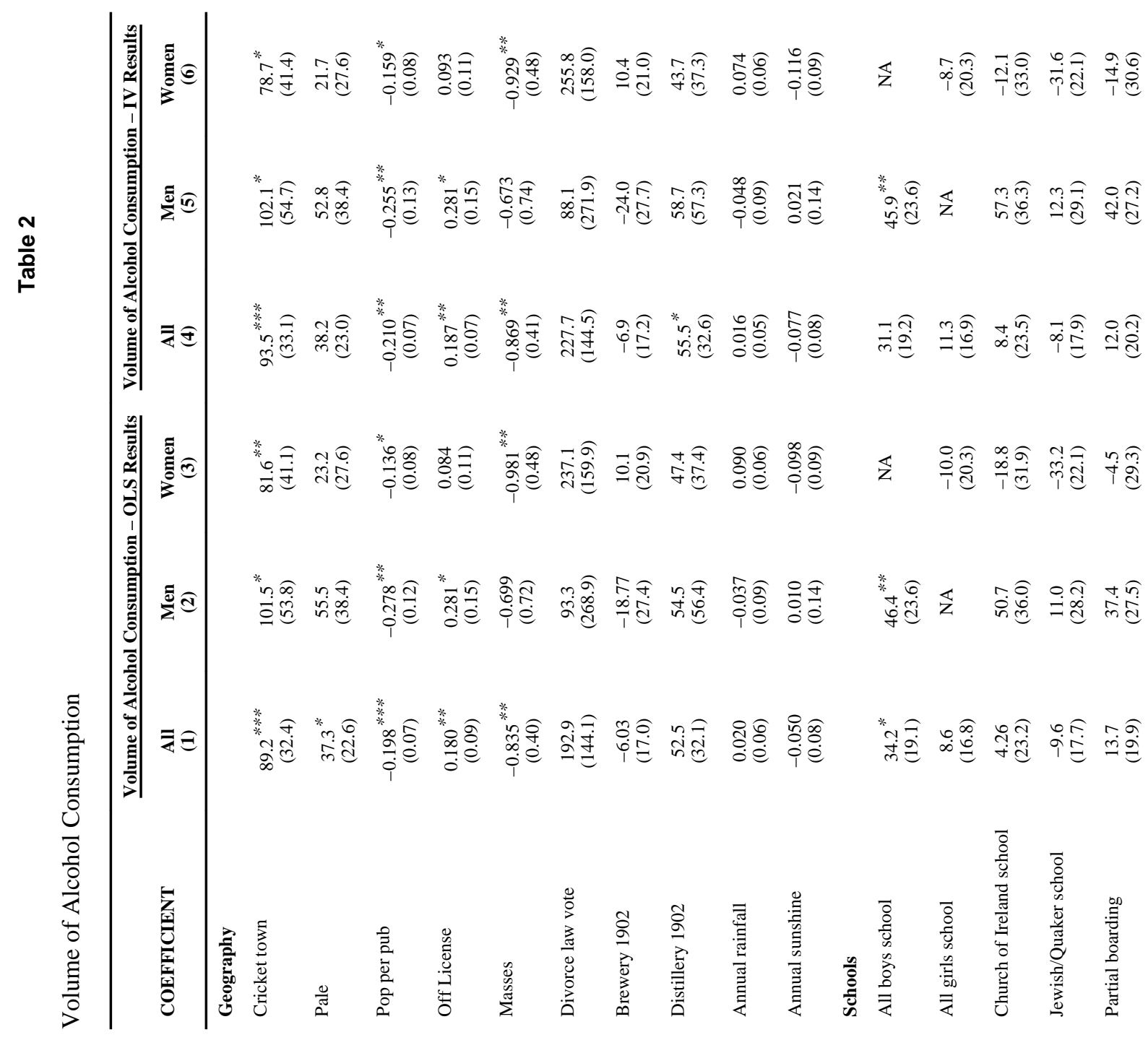




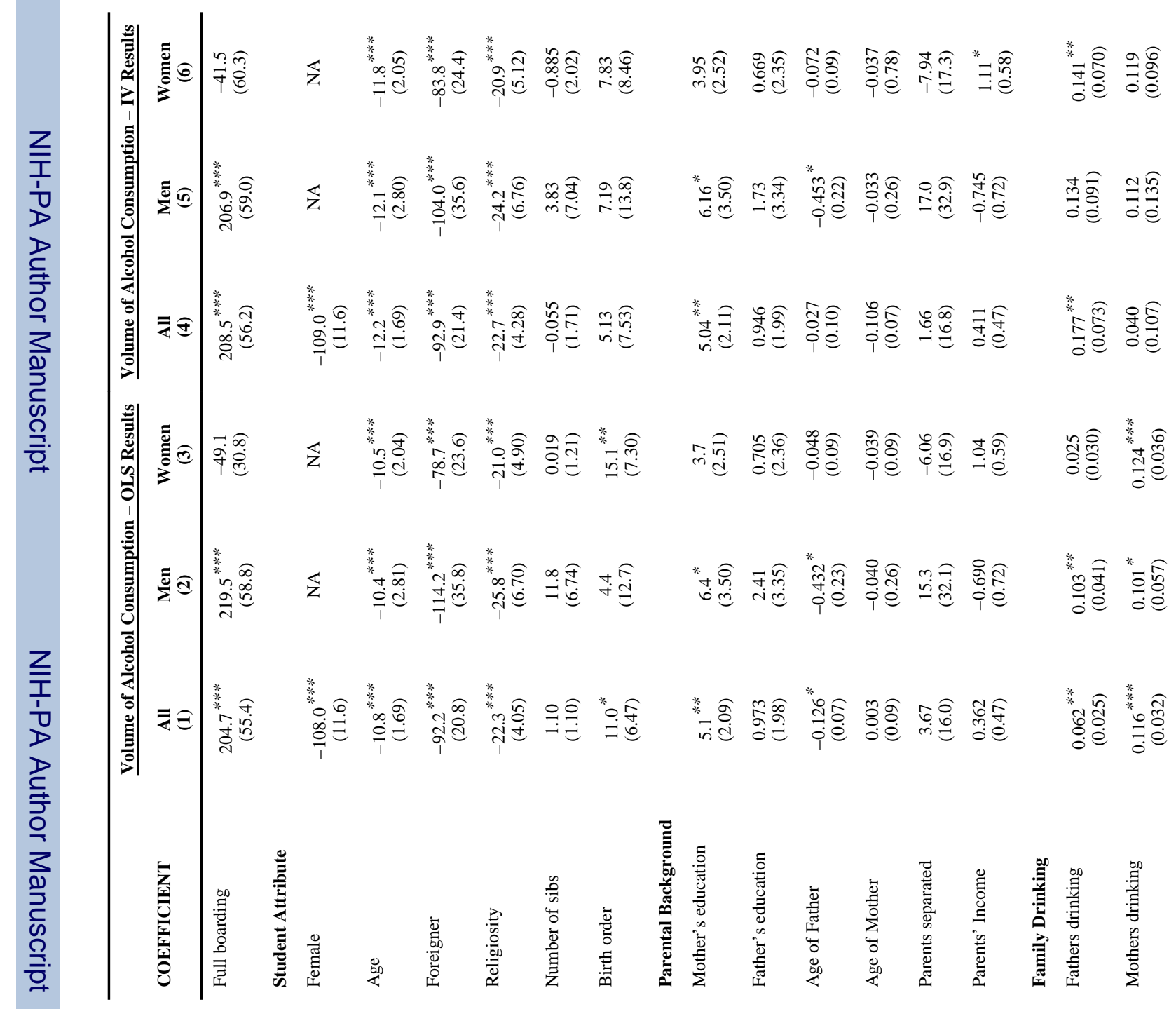




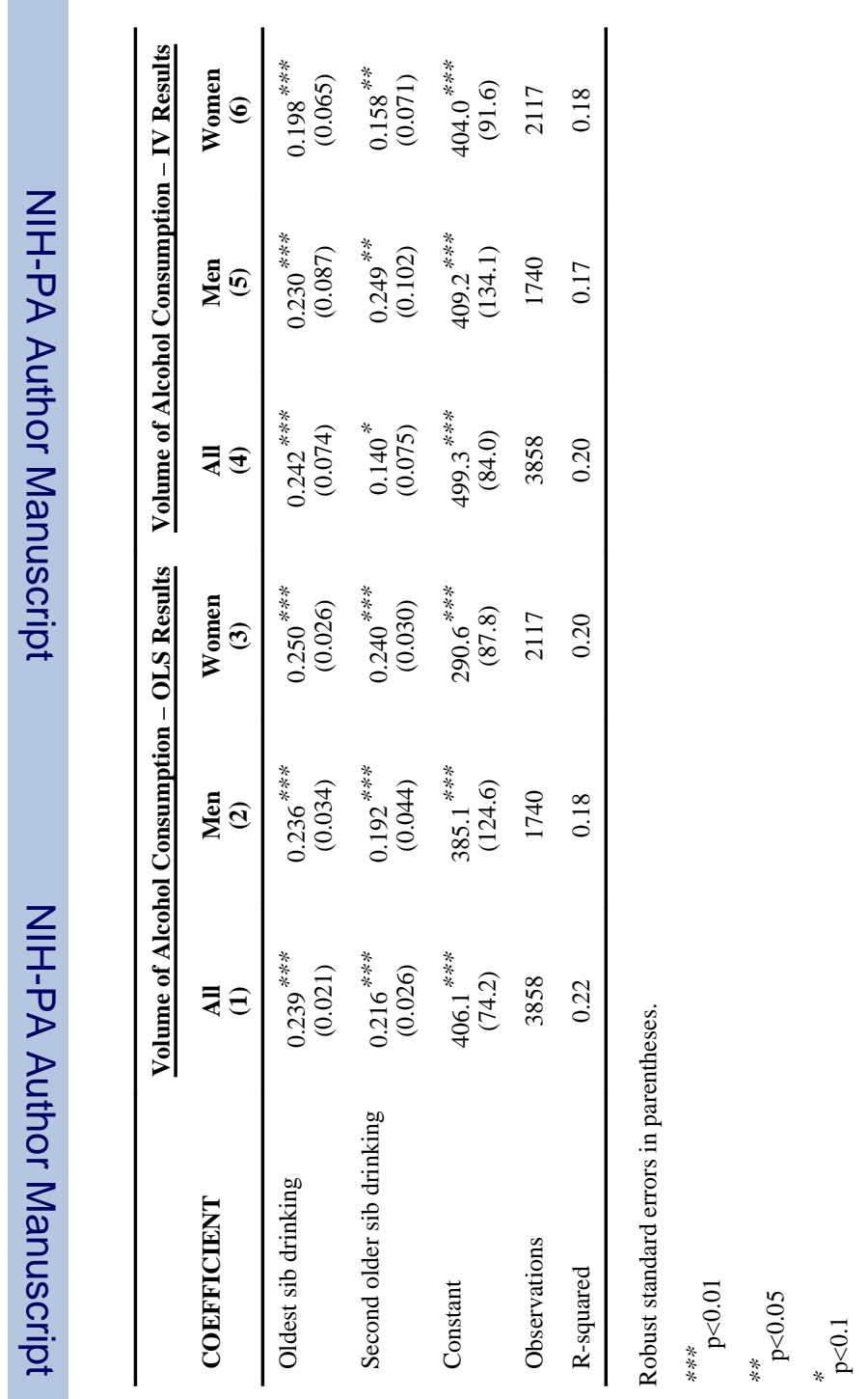


.

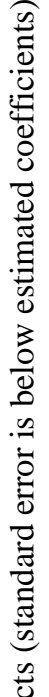

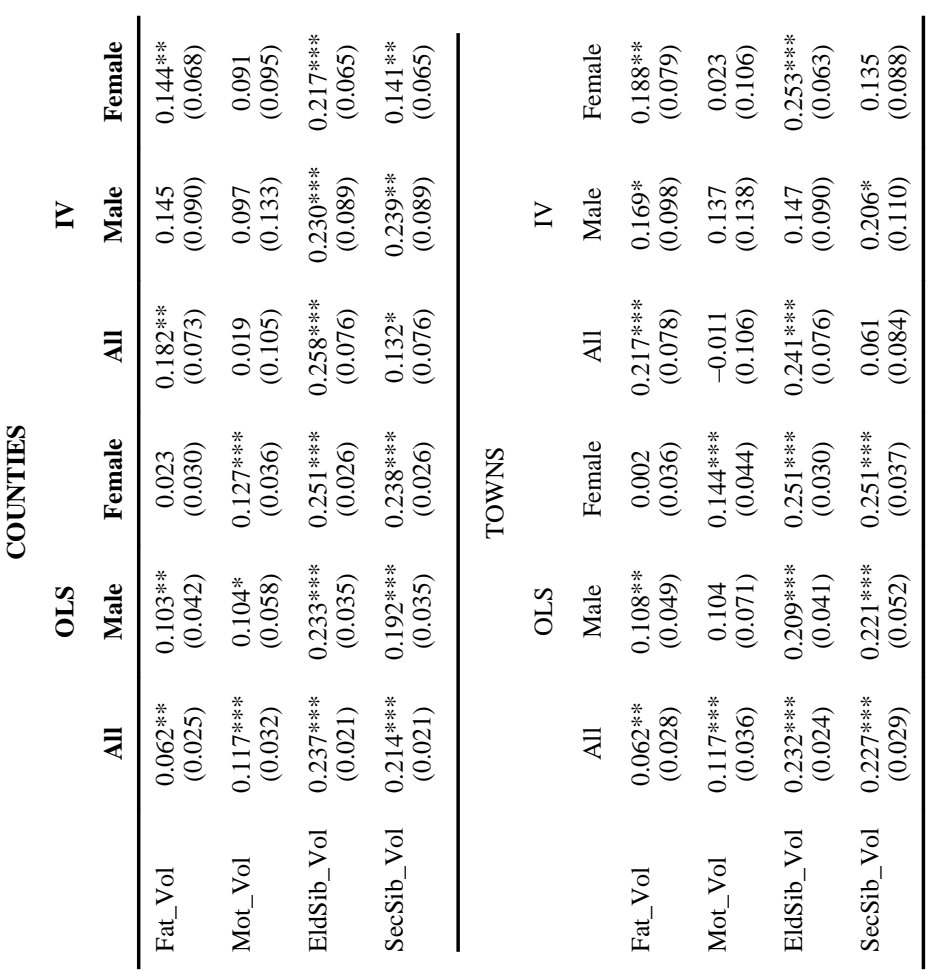




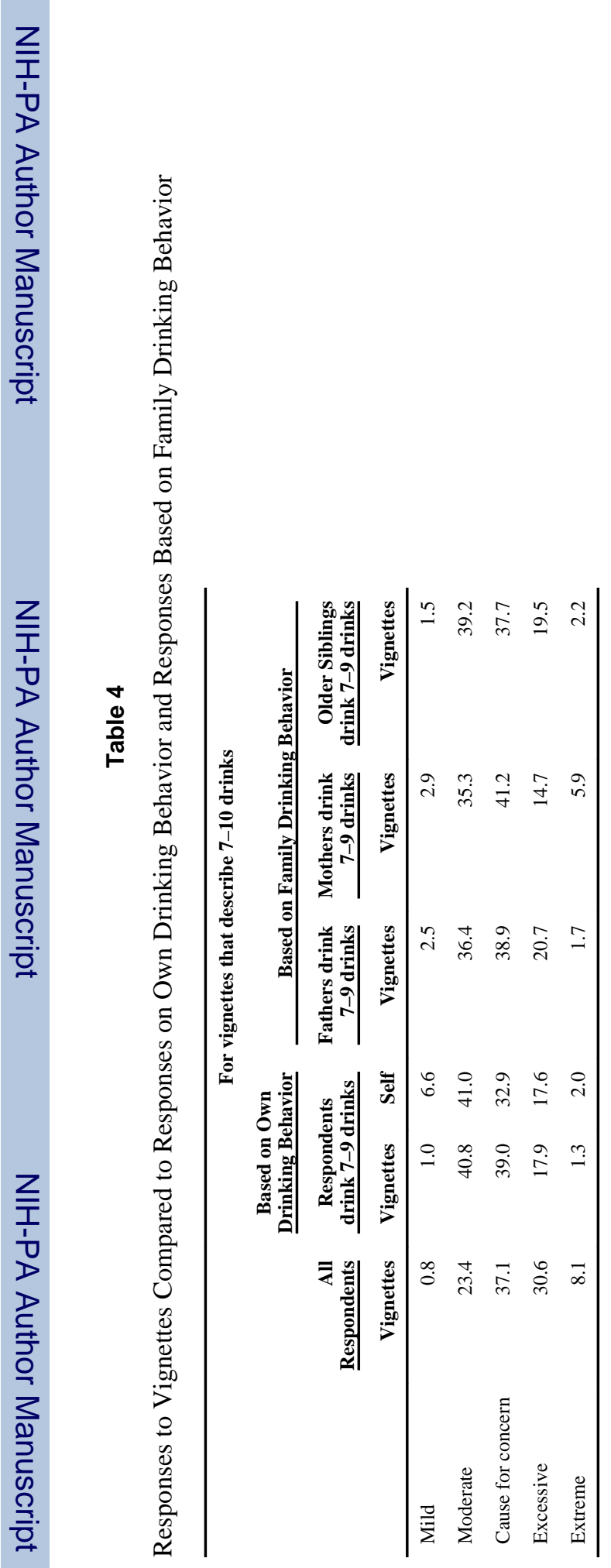

Rev Econ Househ. Author manuscript; available in PMC 2013 May 07. 
Table 5

Ordered Probit for Self-Rated Scale on Alcohol Problems (ordered from mild, moderate, some cause of concern, excessive, extreme)

\begin{tabular}{|c|c|c|c|}
\hline COEFFICIENT & $\begin{array}{l}\text { (1) } \\
\text { All }\end{array}$ & $\begin{array}{l}(2) \\
\text { Men }\end{array}$ & $\begin{array}{c}(3) \\
\text { Women }\end{array}$ \\
\hline \multicolumn{4}{|l|}{ Geography } \\
\hline Cricket town & $\begin{array}{c}0.393^{* * * *} \\
(0.128)\end{array}$ & $\begin{array}{l}0.358^{* *} \\
(0.182)\end{array}$ & $\begin{array}{l}0.417^{* *} \\
(0.184)\end{array}$ \\
\hline Pale & $\begin{array}{c}0.022 \\
(0.096)\end{array}$ & $\begin{array}{c}0.123 \\
(0.138)\end{array}$ & $\begin{array}{l}-0.094 \\
(0.137)\end{array}$ \\
\hline Pop per pub & $\begin{array}{c}-0.001^{* * * *} \\
(0.000)\end{array}$ & $\begin{array}{c}-0.001^{* *} \\
(0.000)\end{array}$ & $\begin{array}{c}-0.001^{* *} \\
(0.000)\end{array}$ \\
\hline Off License & $\begin{array}{l}0.001^{*} \\
(0.000)\end{array}$ & $\begin{array}{l}0.001 * \\
(0.001)\end{array}$ & $\begin{array}{c}0.000 \\
(0.001)\end{array}$ \\
\hline Masses & $\begin{array}{c}-0.004^{* *} \\
(0.002)\end{array}$ & $\begin{array}{l}-0.003 \\
(0.002)\end{array}$ & $\begin{array}{c}-0.005^{* *} \\
(0.002)\end{array}$ \\
\hline Divorce law vote & $\begin{array}{c}0.977 \\
(0.634)\end{array}$ & $\begin{array}{c}0.079 \\
(0.9492)\end{array}$ & $\begin{array}{l}1.790^{* *} \\
(0.838)\end{array}$ \\
\hline Brewery 1902 & $\begin{array}{l}-0.051 \\
(0.065)\end{array}$ & $\begin{array}{l}-0.124 \\
(0.089)\end{array}$ & $\begin{array}{c}0.058 \\
(0.094)\end{array}$ \\
\hline Distillery 1902 & $\begin{array}{l}0.270^{* * *} \\
(0.124)\end{array}$ & $\begin{array}{c}0.286 \\
(0.175)\end{array}$ & $\begin{array}{c}0.239 \\
(0.176)\end{array}$ \\
\hline Annual rainfall & $\begin{array}{c}0.000 \\
(0.000)\end{array}$ & $\begin{array}{l}-0.000 \\
(0.000)\end{array}$ & $\begin{array}{l}0.001^{* *} \\
(0.000)\end{array}$ \\
\hline Annual sunshine & $\begin{array}{l}-0.000 \\
(0.000)\end{array}$ & $\begin{array}{c}0.000 \\
(0.001)\end{array}$ & $\begin{array}{c}-0.001^{* *} \\
(0.000)\end{array}$ \\
\hline \multicolumn{4}{|l|}{ Schools } \\
\hline All boys school & $\begin{array}{c}0.072 \\
(0.073)\end{array}$ & $\begin{array}{c}0.049 \\
(0.083)\end{array}$ & NA \\
\hline All girls school & $\begin{array}{c}0.046 \\
(0.070)\end{array}$ & NA & $\begin{array}{c}0.072 \\
(0.092)\end{array}$ \\
\hline Church of Ireland school & $\begin{array}{c}0.119 \\
(0.091)\end{array}$ & $\begin{array}{c}0.090 \\
(0.126)\end{array}$ & $\begin{array}{l}0.310^{* * *} \\
(0.1491)\end{array}$ \\
\hline Jewish/Quaker school & $\begin{array}{l}-0.072 \\
(0.074)\end{array}$ & $\begin{array}{l}-0.078 \\
(0.106)\end{array}$ & $\begin{array}{l}-0.064 \\
(0.105)\end{array}$ \\
\hline Partial boarding & $\begin{array}{c}0.034 \\
(0.079)\end{array}$ & $\begin{array}{c}0.119 \\
(0.102)\end{array}$ & $\begin{array}{l}-0.223 \\
(0.136)\end{array}$ \\
\hline Full boarding & $\begin{array}{c}0.482^{* * *} \\
(0.161)\end{array}$ & $\begin{array}{c}0.543^{* * * *} \\
(0.158)\end{array}$ & $\begin{array}{c}-0.702^{*} \\
(0.370)\end{array}$ \\
\hline \multicolumn{4}{|l|}{ Student Attribute } \\
\hline Female & $\begin{array}{c}-0.281^{* * * *} \\
(0.049)\end{array}$ & NA & NA \\
\hline Age & $\begin{array}{c}-0.057^{* * * *} \\
(0.008)\end{array}$ & $\begin{array}{c}-0.057^{* * * *} \\
(0.012)\end{array}$ & $\begin{array}{c}-0.059^{* * *} \\
(0.011)\end{array}$ \\
\hline Foreigner & $\begin{array}{l}-0.154 \\
(0.103)\end{array}$ & $\begin{array}{l}-0.187 \\
(0.150)\end{array}$ & $\begin{array}{l}-0.149 \\
(0.143)\end{array}$ \\
\hline Religiosity & $\begin{array}{c}-0.067^{* * * *} \\
(0.019)\end{array}$ & $\begin{array}{c}-0.058^{* *} \\
(0.027)\end{array}$ & $\begin{array}{c}-0.094^{* * * *} \\
(0.027)\end{array}$ \\
\hline
\end{tabular}

Rev Econ Househ. Author manuscript; available in PMC 2013 May 07. 


\begin{tabular}{|c|c|c|c|}
\hline COEFFICIENT & $\begin{array}{l}\text { (1) } \\
\text { All }\end{array}$ & $\begin{array}{l}(2) \\
\text { Men }\end{array}$ & $\begin{array}{c}\text { (3) } \\
\text { Women }\end{array}$ \\
\hline Number of sibs & $\begin{array}{l}-0.001 \\
(0.006)\end{array}$ & $\begin{array}{l}0.057^{*} \\
(0.029)\end{array}$ & $\begin{array}{c}-0.011^{* *} \\
(0.005)\end{array}$ \\
\hline Birth order & $\begin{array}{c}0.005 \\
(0.031)\end{array}$ & $\begin{array}{l}-0.064 \\
(0.050)\end{array}$ & $\begin{array}{c}0.031 \\
(0.042)\end{array}$ \\
\hline \multicolumn{4}{|l|}{ Parental Background } \\
\hline Mother's education & $\begin{array}{c}0.002 \\
(0.010)\end{array}$ & $\begin{array}{l}-0.001 \\
(0.014)\end{array}$ & $\begin{array}{c}0.004 \\
(0.013)\end{array}$ \\
\hline Father's education & $\begin{array}{c}0.012 \\
(0.009)\end{array}$ & $\begin{array}{c}0.015 \\
(0.012)\end{array}$ & $\begin{array}{c}0.013 \\
(0.012)\end{array}$ \\
\hline Age of Father & $\begin{array}{c}-0.001^{* * * *} \\
(0.000)\end{array}$ & $\begin{array}{l}-0.001 \\
(0.001)\end{array}$ & $\begin{array}{c}-0.001^{* *} \\
(0.000)\end{array}$ \\
\hline Age of Mother & $\begin{array}{c}0.000 \\
(0.000)\end{array}$ & $\begin{array}{c}0.001 \\
(0.001)\end{array}$ & $\begin{array}{c}0.000 \\
(0.000)\end{array}$ \\
\hline Parents separated & $\begin{array}{l}-0.001 \\
(0.073)\end{array}$ & $\begin{array}{l}-0.100 \\
(0.125)\end{array}$ & $\begin{array}{c}0.031 \\
(0.092)\end{array}$ \\
\hline Parents' Income & $\begin{array}{c}0.001 \\
(0.002)\end{array}$ & $\begin{array}{l}-0.003 \\
(0.003)\end{array}$ & $\begin{array}{c}0.002 \\
(0.002)\end{array}$ \\
\hline \multicolumn{4}{|l|}{ Family Drinking } \\
\hline Fathers drinking & $\begin{array}{c}0.001 \\
(0.010)\end{array}$ & $\begin{array}{c}0.008 \\
(0.015)\end{array}$ & $\begin{array}{l}-0.001 \\
(0.014)\end{array}$ \\
\hline Mothers drinking & $\begin{array}{c}0.032^{* * * *} \\
(0.012)\end{array}$ & $\begin{array}{c}0.015 \\
(0.019)\end{array}$ & $\begin{array}{c}0.049^{* * * *} \\
(0.016)\end{array}$ \\
\hline Oldest sib drinking & $\begin{array}{c}0.058^{* * * *} \\
(0.008)\end{array}$ & $\begin{array}{c}0.046^{* * * *} \\
(0.012)\end{array}$ & $\begin{array}{c}0.071^{* * * *} \\
(0.011)\end{array}$ \\
\hline Second older sib drinking & $\begin{array}{c}0.055^{* * * *} \\
(0.009)\end{array}$ & $\begin{array}{c}0.036^{* * *} \\
(0.014)\end{array}$ & $\begin{array}{c}0.077^{* * * *} \\
(0.012)\end{array}$ \\
\hline \multicolumn{4}{|l|}{ Miscellaneous } \\
\hline Cut point 1 & $\begin{array}{c}-1.730^{* * *} \\
(0.325)\end{array}$ & $\begin{array}{c}-1.735^{* * * *} \\
(0.482)\end{array}$ & $\begin{array}{c}-1.395^{* * * *} \\
(0.442)\end{array}$ \\
\hline Cut point 2 & $\begin{array}{l}-0.471 \\
(0.324)\end{array}$ & $\begin{array}{l}-0.569 \\
(0.480)\end{array}$ & $\begin{array}{l}-0.038 \\
(0.442)\end{array}$ \\
\hline Cut point 3 & $\begin{array}{c}0.252 \\
(0.324)\end{array}$ & $\begin{array}{c}0.170 \\
(0.479)\end{array}$ & $\begin{array}{c}0.685 \\
(0.444)\end{array}$ \\
\hline Cut point 4 & $\begin{array}{c}1.297^{* * * *} \\
(0.327)\end{array}$ & $\begin{array}{l}1.215^{* * *} \\
(0.485)\end{array}$ & $\begin{array}{c}1.755^{* * * *} \\
(0.448)\end{array}$ \\
\hline $\begin{array}{l}\text { Observations } \\
\text { R-squared }\end{array}$ & 3667 & 1645 & 2021 \\
\hline
\end{tabular}

Robust standard errors in parentheses.

$* * *$

$\mathrm{p}<0.01$

*** $<0.05$

$\mathrm{p}<0.1$ 
Table 6

Ordered Probit for Response Scale for Quantity Vignettes (ordered from mild, moderate, some cause of concern, excessive, extreme)

\begin{tabular}{|c|c|c|c|}
\hline COEFFICIENT & $\begin{array}{l}\text { (1) } \\
\text { All }\end{array}$ & $\begin{array}{l}(2) \\
\text { Men }\end{array}$ & $\begin{array}{c}\text { (3) } \\
\text { Women }\end{array}$ \\
\hline \multicolumn{4}{|l|}{ Geography } \\
\hline Cricket town & $\begin{array}{c}0.001 \\
(0.136)\end{array}$ & $\begin{array}{l}-0.053 \\
(0.167)\end{array}$ & $\begin{array}{l}-0.040 \\
(0.226)\end{array}$ \\
\hline Pale & $\begin{array}{c}0.022 \\
(0.102)\end{array}$ & $\begin{array}{c}0.106 \\
(0.154)\end{array}$ & $\begin{array}{l}-0.073 \\
(0.136)\end{array}$ \\
\hline Pop per pub & $\begin{array}{c}0.000 \\
(0.000)\end{array}$ & $\begin{array}{l}-0.000 \\
(0.001)\end{array}$ & $\begin{array}{c}0.000 \\
(0.000)\end{array}$ \\
\hline Off license & $\begin{array}{l}-0.001 \\
(0.000)\end{array}$ & $\begin{array}{c}-0.001^{* *} \\
(0.001)\end{array}$ & $\begin{array}{l}-0.000 \\
(0.001)\end{array}$ \\
\hline Masses & $\begin{array}{c}0.001 \\
(0.002)\end{array}$ & $\begin{array}{c}0.001 \\
(0.002)\end{array}$ & $\begin{array}{c}0.002 \\
(0.003)\end{array}$ \\
\hline Divorce law vote & $\begin{array}{l}-0.417 \\
(0.641)\end{array}$ & $\begin{array}{l}-0.696 \\
(0.949)\end{array}$ & $\begin{array}{l}-0.541 \\
(0.849)\end{array}$ \\
\hline Brewery 1902 & $\begin{array}{l}-0.058 \\
(0.071)\end{array}$ & $\begin{array}{l}-0.140 \\
(0.092)\end{array}$ & $\begin{array}{c}0.007 \\
(0.113)\end{array}$ \\
\hline Distillery 1902 & $\begin{array}{c}0.007 \\
(0.132)\end{array}$ & $\begin{array}{c}0.093 \\
(0.151)\end{array}$ & $\begin{array}{l}-0.104 \\
(0.225)\end{array}$ \\
\hline Annual rainfall & $\begin{array}{l}-0.000 \\
(0.000)\end{array}$ & $\begin{array}{l}-0.000 \\
(0.000)\end{array}$ & $\begin{array}{l}-0.000 \\
(0.000)\end{array}$ \\
\hline Annual sunshine & $\begin{array}{c}0.000 \\
(0.000)\end{array}$ & $\begin{array}{c}0.000 \\
(0.001)\end{array}$ & $\begin{array}{c}0.000 \\
(0.000)\end{array}$ \\
\hline \multicolumn{4}{|l|}{ Schools } \\
\hline All boys school & $\begin{array}{c}0.103 \\
(0.078)\end{array}$ & $\begin{array}{c}0.101 \\
(0.088)\end{array}$ & NA \\
\hline All girls school & $\begin{array}{c}0.038 \\
(0.075)\end{array}$ & NA & $\begin{array}{c}0.083 \\
(0.094)\end{array}$ \\
\hline Church of Ireland school & $\begin{array}{l}-0.030 \\
(0.098)\end{array}$ & $\begin{array}{c}-0.086 \\
(0.1421)\end{array}$ & $\begin{array}{c}0.093 \\
(0.164)\end{array}$ \\
\hline Jewish/Quaker school & $\begin{array}{c}0.058 \\
(0.076)\end{array}$ & $\begin{array}{c}0.129 \\
(0.108)\end{array}$ & $\begin{array}{c}0.016 \\
(0.110)\end{array}$ \\
\hline Partial boarding & $\begin{array}{c}0.028 \\
(0.088)\end{array}$ & $\begin{array}{c}0.064 \\
(0.108)\end{array}$ & $\begin{array}{l}-0.044 \\
(0.168)\end{array}$ \\
\hline Full boarding & $\begin{array}{l}-0.177 \\
(0.200)\end{array}$ & $\begin{array}{l}-0.213 \\
(0.203)\end{array}$ & $\begin{array}{c}-9.169^{* * * *} \\
(0.210)\end{array}$ \\
\hline \multicolumn{4}{|l|}{ Student Attribute } \\
\hline Female & $\begin{array}{c}0.127^{* *} \\
(0.061)\end{array}$ & NA & NA \\
\hline Age & $\begin{array}{l}0.016^{*} \\
(0.009)\end{array}$ & $\begin{array}{l}0.025^{*} \\
(0.013)\end{array}$ & $\begin{array}{c}0.013 \\
(0.012)\end{array}$ \\
\hline Foreigner & $\begin{array}{c}0.655^{* * * *} \\
(0.123)\end{array}$ & $\begin{array}{c}0.779^{* * * *} \\
(0.191)\end{array}$ & $\begin{array}{c}0.634^{* * * *} \\
(0.164)\end{array}$ \\
\hline Religiosity & $\begin{array}{c}0.078^{* * * *} \\
(0.020)\end{array}$ & $\begin{array}{l}0.064^{* * *} \\
(0.030)\end{array}$ & $\begin{array}{c}0.099^{* * * *} \\
(0.027)\end{array}$ \\
\hline Number of sibs & $\begin{array}{l}0.023^{* *} \\
(0.009)\end{array}$ & $\begin{array}{l}-0.015 \\
(0.031)\end{array}$ & $\begin{array}{c}0.033^{* * *} \\
(0.013)\end{array}$ \\
\hline
\end{tabular}




\begin{tabular}{|c|c|c|c|}
\hline COEFFICIENT & $\begin{array}{l}\text { (1) } \\
\text { All }\end{array}$ & $\begin{array}{l}\text { (2) } \\
\text { Men }\end{array}$ & $\begin{array}{c}(3) \\
\text { Women }\end{array}$ \\
\hline Birth order & $\begin{array}{l}-0.006 \\
(0.018)\end{array}$ & $\begin{array}{l}0.005 \\
(0.033)\end{array}$ & $\begin{array}{l}-0.001 \\
(0.024)\end{array}$ \\
\hline \multicolumn{4}{|l|}{ Parental Background } \\
\hline Mother's education & $\begin{array}{l}-0.004 \\
(0.010)\end{array}$ & $\begin{array}{c}0.005 \\
(0.015)\end{array}$ & $\begin{array}{l}-0.011 \\
(0.013)\end{array}$ \\
\hline Father's education & $\begin{array}{c}0.011 \\
(0.009)\end{array}$ & $\begin{array}{c}0.009 \\
(0.014)\end{array}$ & $\begin{array}{c}0.009 \\
(0.012)\end{array}$ \\
\hline Age of Father & $\begin{array}{c}0.000 \\
(0.000)\end{array}$ & $\begin{array}{l}0.002^{* * *} \\
(0.001)\end{array}$ & $\begin{array}{l}-0.000 \\
(0.000)\end{array}$ \\
\hline Age of Mother & $\begin{array}{c}0.000 \\
(0.000)\end{array}$ & $\begin{array}{l}-0.001 \\
(0.001)\end{array}$ & $\begin{array}{c}0.000 \\
(0.000)\end{array}$ \\
\hline Parents separated & $\begin{array}{c}0.080 \\
(0.075)\end{array}$ & $\begin{array}{c}0.007 \\
(0.121)\end{array}$ & $\begin{array}{l}0.173^{*} \\
(0.096)\end{array}$ \\
\hline Parents' income & $\begin{array}{l}-0.002 \\
(0.002)\end{array}$ & $\begin{array}{l}-0.002 \\
(0.004)\end{array}$ & $\begin{array}{l}-0.002 \\
(0.002)\end{array}$ \\
\hline \multicolumn{4}{|l|}{ Family Drinking } \\
\hline Fathers drinking & $\begin{array}{l}-0.014 \\
(0.010)\end{array}$ & $\begin{array}{l}-0.017 \\
(0.016)\end{array}$ & $\begin{array}{c}-0.011 \\
(0.0148)\end{array}$ \\
\hline Mothers drinking & $\begin{array}{c}-0.029^{* * *} \\
(0.014)\end{array}$ & $\begin{array}{c}-0.041^{*} \\
(0.021)\end{array}$ & $\begin{array}{l}-0.024 \\
(0.019)\end{array}$ \\
\hline Oldest sib drinking 1 & $\begin{array}{c}-0.043^{* * * *} \\
(0.009)\end{array}$ & $\begin{array}{c}-0.029^{* *} \\
(0.013)\end{array}$ & $\begin{array}{c}-0.058^{* * * *} \\
(0.012)\end{array}$ \\
\hline Second older sib drinking 1 & $\begin{array}{c}-0.040^{* * *} \\
(0.010)\end{array}$ & $\begin{array}{l}-0.016 \\
(0.015)\end{array}$ & $\begin{array}{c}-0.061^{* * *} \\
(0.014)\end{array}$ \\
\hline \multicolumn{4}{|l|}{ Miscellaneous } \\
\hline Female name in vignette & $\begin{array}{c}0.127^{* * * *} \\
(0.025)\end{array}$ & $\begin{array}{c}0.185^{* * * *} \\
(0.039)\end{array}$ & $\begin{array}{c}0.078^{* *} \\
(0.034)\end{array}$ \\
\hline Cut point 1 & $\begin{array}{c}2.100^{* * * *} \\
(0.3852)\end{array}$ & $\begin{array}{c}2.326^{* * * *} \\
(0.632)\end{array}$ & $\begin{array}{c}1.946^{* * *} \\
(0.479)\end{array}$ \\
\hline Cut point 2 & $\begin{array}{c}3.797^{* * * *} \\
(0.391)\end{array}$ & $\begin{array}{c}3.972^{* * * *} \\
(0.640)\end{array}$ & $\begin{array}{c}3.730 \text { *** } \\
(0.488)\end{array}$ \\
\hline Cut point 3 & $\begin{array}{c}4.787^{* * *} \\
(0.395)\end{array}$ & $\begin{array}{c}4.967^{* * *} \\
(0.644)\end{array}$ & $\begin{array}{c}4.734^{* * *} \\
(0.493)\end{array}$ \\
\hline Cut point 4 & $\begin{array}{c}5.757^{* * * *} \\
(0.403)\end{array}$ & $\begin{array}{c}5.867^{* * * *} \\
(0.656)\end{array}$ & $\begin{array}{c}5.781^{* * *} \\
(0.503)\end{array}$ \\
\hline Observations & 3320 & 1505 & 1814 \\
\hline
\end{tabular}

Robust standard errors in parentheses.

***

$\mathrm{p}<0.01$

*** $\mathrm{p}<0.05$

*

$\mathrm{p}<0.1$ 
$\frac{3}{8}$

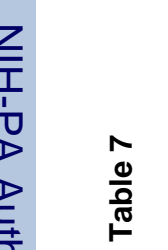

$\bar{c}$

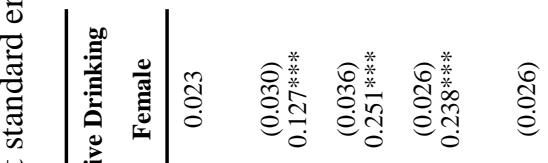
蒫

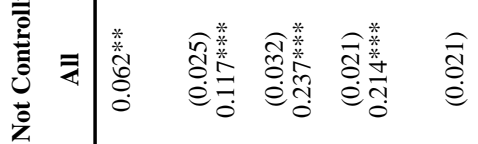

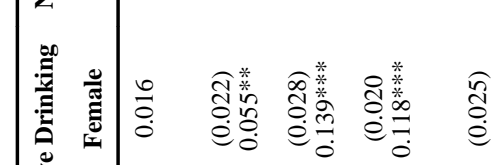

